\title{
Angle-resolved Neutralization-Reionization Mass Spectrometry
}

\author{
Aberra Fura, Frantisek Turecek," and Fred W. McLafferty \\ Department of Chemistry, Cornell University, Ithaca, New York, USA
}

Neutralization-reionization mass spectra of 2-propenal, isomeric butenes, and isomeric $n$-hexenes have been found to depend significantly on the $z$-axis scattering angle of the neutralization event. As shown by Cooks for ion dissociations, increasing scattering angles generally favor products of higher activation-energy reactions. For isomeric butenes and $n$-hexenes, these reactions provide more definitive information for isomeric characlerization. (J Am Soc Mass Spectrom 1991, 2, 492-496)

$\mathrm{T}$ The unimolecular dissociation of neutral species effected in neutralization-reionization mass spectrometry (NRMS) [1-6] can provide structural information not available in normal mass spectra; for the latter, ionic species are dissociated. The favored dissociation pathways of neutrals can be different than those of the corresponding ions; the bonds of lowest dissociation energy in neutral and ionized methanol are $\mathrm{H}_{3} \mathrm{C}-\mathrm{OH}$ and $\mathrm{H}-\mathrm{CH}_{2} \mathrm{OH}^{+}$. An even more useful difference, however, is that neutralization generally increases the energy required for unimolecular isomerization [7-9], so that the competing dissociation reactions yield products more characteristic of the original structure. For both ions and neutrals, a well-known technique for favoring dissociation over isomerization is to increase the internal energy of the reacting species sufficiently to take advantage of the lower entropy penalty of simple dissociation reactions.

Several ways have been used to increase the proportion of high energy dissociations of neutrals. Porter and co-workers [2] showed that neutralization targets of low ionization potential (IP), such as alkali metals, can produce excited neutrals directly, with their internal energy determined by the difference between the electron affinity of the ion neutralized and the IP value of the metal (as described recently, organic molecules can also serve as neutralization agents [10]). This has been utilized, for example, to distinguish five $\mathrm{C}_{4} \mathrm{H}_{8}^{1} \cdot$ ionic isomers [8]. A second method is analogous to the collisionally activated dissociation (CAD) of ions [11]; subjecting the newly formed neutral to

\footnotetext{
* Present address: Department of Chemistry, University of Washing ton, Seattle, WA 98195 .

Address correspondence to Fred W. McLafferty, Baker Chemistry Laboratory, Comell University, Ithaca, NY 14853-1301.
}

collisions with a gas such as helium can produce CAD of these neutrals, with subsequent ionization of the products. The NCR mass spectra thus produced have provided key information for a variety of problems [3, $6,7,9,12,13]$.

For inns, another method to increase the contribution to $\mathrm{CAD}$ mass spectra of product ions from higher energy reactions is to select those scattered at larger angles; such "angle-resolved" mass spectrometry (ARMS) was pioneered by Cooks and co-workers [14-19], with important contributions from other laboratories [20-24]. Evidence has been offered that this angular dependence results from collisional energy deposition and/or kinetic energy release in the dissociation. We report here the extension of this ARMS technique to the CAD of neutrals to produce characteristic angle-resolved neutralization-reionization (ARNR) spectra of 2-propenal, isomeric butenes, and isomeric $n$-hexenes.

\section{Experimental}

The tandem double-focusing mass spectrometer (EBEB) [25] uses 70-eV electrons to produce precursor ions that are accelerated by $10 \mathrm{keV}$ and mass analyzed by MS-I (EB). These ions undergo charge exchange with $\mathrm{Hg}$ in the furst collision cell (Cls-I), the remaining ions are removed electrostatically, and the neutral heam undergoes collisional ionization with $\mathrm{O}_{2}$ in the second collision cell (Cls-II). These ions are focused by a large (20-mm internal width) Einzel lens with $x$, $y$-plane symmetry (no $z$-axis focusing) and are then mass analyzed in the second electrostatic analyzer to produce the normal NR mass spectrum. For ARNR spectra (Figure 1), the precursor ions are deflected in the $z$-axis electrostatically (25-mm-long deflection plates, $20 \mathrm{~mm}$ apart) just before the MS-I exit slit 
$(\sim 0.1 \times 8 \mathrm{~mm})$ and Cls-I; otherwise, the ion optical elements are unchanged. The collision cell and differential pumping slits [25] are $\sim 10 \mathrm{~mm}$ high (1-4 $\mathrm{mm}$ wide), and so should not interfere appreciably. The $z$-axis is the long (vertical) dimension of the rectangular cross-section ion beam; because the neutrals formed in Cls-I are unaffected by the electric fields, their path and the path of ions formed from them reflect the $z$-axis velocity component of the deflected precursor ions. Thus for transmission through the instrument, deflection of the precursor ion beam ( $8 \mathrm{~mm}$ high) must be offset sufficiently by collisional scattering so as not to exceed the acceptance angle of $0.29^{\circ}$ defined by the 8-mm-high $(0.2-0.5$ mm wide) ESA-II exit slit ( $\beta^{\prime}$-slit) located $159 \mathrm{~cm}$ from the deflector. The precursor beam deflection can also be offset by scattering in the reionization process; however, the Einzel lens already focuses and transmits a substantial proportion of such $y$-axis scattering, so that the relative effect of $z$-axis ion scattering should be much less than that for neutrals. Ion trajectory simulations using SIMION [26] predict that a vertical deflector potential of $72 \mathrm{~V}$ deflects the beam by $0.29^{\circ}$. This corresponds to a $z$-velocity of $830 \mathrm{~m} / \mathrm{s}$ and a $z$-component of kinetic energy of $0.20 \mathrm{eV}$. The vertical deflector magnifies the height of the slit image from 8 to $8.5 \mathrm{~mm}$ at the $\beta^{\prime}$-slit position. For deflection potentials of 40 and $80 \mathrm{~V}$, the calculated transmittances are $\sim 50 \%$ and $0 \%$, respectively. The experimentally observed values are $-50 \%$ and a few percent, respectively, indicating that the precursor ion beam has been well collimated in the $x-z$ plane by the double-focusing MS-I.

The abbreviation $\mathrm{Hg}(70 \% \mathrm{~T}) / \mathrm{O}_{2}(50 \% \mathrm{~T})$ signifies neutralization with $\mathrm{Hg}$ at $70 \%$ transmittance of the precursor ion, residual ion deflection (slash), and reionization of the neutrals with $\mathrm{O}_{2}$ at $50 \%$ transmittance of the precursor ion $[12,25]$. The chemicals were used as obtained commercially.

\section{Results and Discussion}

Angle-resolved mass spectrometry of ions has utilized deflection in the narrow dimension of the ion beam at a focal point in the ion path, with selection at a subsequent focal point, as angular resolution is dependent on the restricted dimension of the beam [14-24]. Unfortunately, for our NRMS experimental configuration, such $y$-axis deflection of the ion beam ( $\sim 0.1 \mathrm{~mm}$ wide), or displacement of it in the $y$-axis by moving the MS-I exit slit horizontally, produced little change in product relative abundances with decreasing absolute abundances. Apparently this is due to the $y$-axis divergence of the unfocused neutral beam leaving the neutralization chamber and to the efficient focusing of the reionized beam by the large planar-symmetrical Einzel lens in front of the MS-II entrance slit; horizontal deflection of an undissociated ion beam by a distance many times this slit width is required to halve the transmitted intensity. However, by deflecting the ion beam ( $8 \mathrm{~mm}$ high) vertically just before the MS-I exit slit (Figure 1), neutrals formed in Cls-I (or ions formed in Cls-II) with an equal but opposing vertical velocity component will follow the normal optical path through the instrument. Increasing the vertical deflection does cause significant changes in the NR spectral abundances before the abundances are made insignificant (see subsequent illustrations).

\section{2-Propenal}

For the dissociation of newly formed 2-propenal neutrals, the changes in relative product ion abundances with increasing scattering angle (Figure 2) in general reflect the reaction-free energies. Loss of $\mathrm{H}$. , the simple bond dissociation of lowest threshold energy $\left(367 \mathrm{~kJ} \mathrm{~mol}^{-1}\right.$; also the lowest energy dissociation for $\mathrm{CH}_{2}=\mathrm{CHCHO}^{+}$.) [27], is dominant at low scattering angles. With increasing angle, the simple cleavage to form $\mathrm{C}_{2} \mathrm{H}_{3} \cdot$ and $\cdot \mathrm{CHO}$, requiring an additional 20

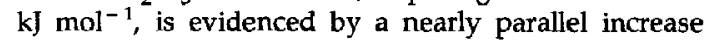
in $\mathrm{m} / \mathrm{z} 27$ and 29 . The products of the entropically unfavorable rearrangements to $\mathrm{C}_{2} \mathrm{H}_{4}+\mathrm{CO}$ and $\mathrm{C}_{2} \mathrm{H}_{2}+\mathrm{CO}+\mathrm{H}_{2}$, requiring 19 and $195 \mathrm{~kJ} \mathrm{~mol}{ }^{1}$, respectively, also show increased relative abundance with increasing scattering angle. The dominant highenergy formation of $\mathrm{C}_{2} \mathrm{H}_{2}$ could possibly arise from dissociation of $\cdot \mathrm{CH}=\mathrm{CHCHO}$ formed in competition with $\mathrm{CH}_{2}=\mathrm{CHCO} \cdot$ at higher energies. Some of

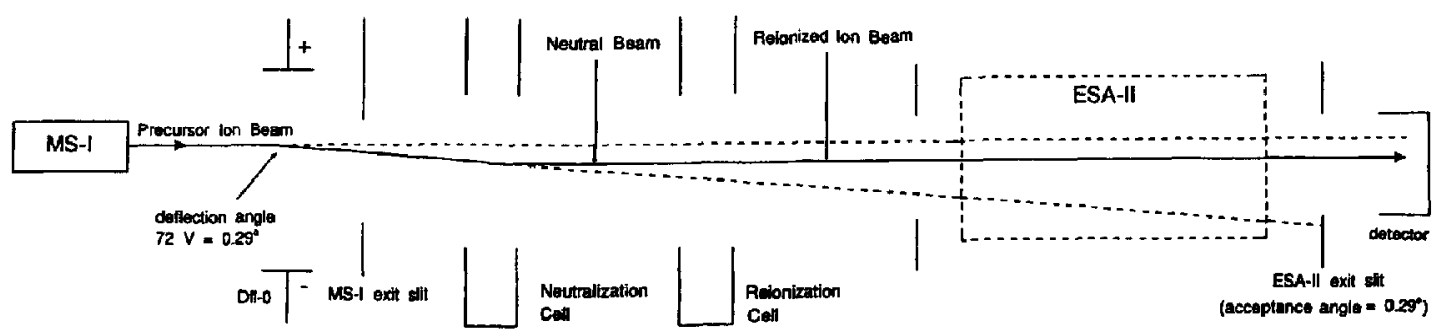

Figure 1. Schematic diagram (side view) of the z-axis beam deflection to measure ARNR spectra.

The horizontal axis is approximately to scale, but the vertical $(z)$ axis is greatly exaggerated. 


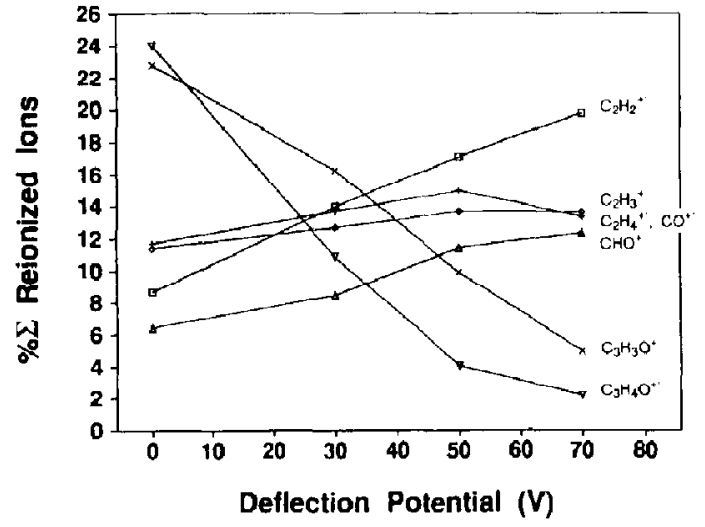

Figure 2. Relative abundances in the NR spectra, $\mathrm{Hg}(70 \% \mathrm{~T}) / \mathrm{O}_{2}(50 \% \mathrm{~T})$, of 2-propenal as a function of deflection potential.

these ions could also be scattered products of reionization in Cls-II; however, such formation of $\mathrm{CHO}^{+}$ and $\mathrm{C}_{2} \mathrm{H}_{3}^{+}$should require 193 and $259 \mathrm{~kJ} \mathrm{~mol}^{-1}$, respectively, predicting an increase in $\left[\mathrm{C}_{2} \mathrm{H}_{3}^{+}\right]$/ $\left[\mathrm{CHO}^{+}\right]$with increasing energy, contrary to the Figure 2 data.

\section{Isomeric Butenes}

As reported earlier [8], normal NRMS spectra of 1butene, E-2-butene, and 2-methylpropene are quite similar, probably because most fragmentation occurs after reionization, effecting ionic isomerization that causes the close similarity of the electron ionization (EI) [28] and CAD [29] mass spectra of the $\mathrm{C}_{4} \mathrm{H}_{8}$ isomers. Feng et al. [8] previously observed that the formation of the $\mathrm{C}_{4} \mathrm{H}_{8}$ neutrals with sufficient energy for fast dissociation was necessary to minimize interference from neutral isomerization. In keeping with this, angle-resolved selection of those products formed by high energy neutral dissociation also substantially increases isomeric differences in the NR mass spectra produced (Figures 3 and 4 ; this also shows that product ions from collisional scattering with reionization at Cls-II do not dominate the ARNR spectra). Methyl loss from 1-butene, E-2-butene, and 2-methylpropene require 307 [27], 406 [30], and 414 [31] $\mathrm{kJ} \mathrm{mol}^{-1}$; this is clearly reflected in the corresponding ARNR mass spectra, with 1-butene ${ }^{+} \cdot$ precursors giving the largest $[m / z 41] /[m / z 56]$ ratio. Higher encrgy fragment ions such as $\mathrm{C}_{3} \mathrm{H}_{3}^{+}$dominate all three ARNR spectra, but isobutene produces a much lower abundance of the $m / z$ 24-29 peaks, consistent with its branched structure. The abundance of $\mathrm{C}_{4} \mathrm{H}_{6}^{+}$. formed by rearrangement loss of $\mathrm{H}_{2}$ is also consistent with the dissociation energies of 110 and $122 \mathrm{~kJ} \mathrm{~mol}^{-1}$ [32] for 1- and 2-butene (formation of 1,3-butadiene), respectively, versus that of $217 \mathrm{~kJ} \mathrm{~mol}^{-1}$ (formation of methylenecyclopropane) [27] for isobutene.
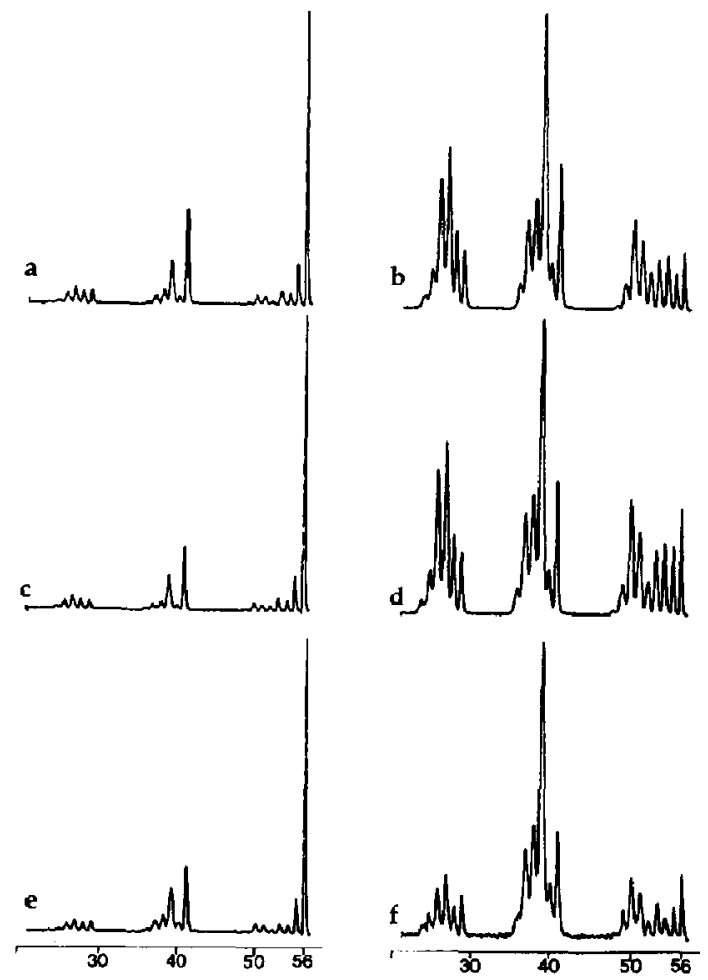

Figure 3. NR spectra, $\mathrm{Hg}(75 \% \mathrm{~T}) / \mathrm{O}_{2}(50 \% \mathrm{~T})$ of (a and b) 1butene, (c and d) E-2-butene, and ( $e$ and $f$ ) 2-methylpropene, using deflection potentials of $(b, c$, and e) $0 \mathrm{~V}$ and $(b, d$, and $f)$ $62 \mathrm{~V}$.

\section{Isomeric $n$-Hexenes}

The EI [28] and CAD [33] mass spectra of 1-, E-2-, and E-3-hexenes do show some characteristic differences, such as the much larger $\mathrm{C}_{3} \mathrm{H}_{6}^{+}$. rearrangement peak in the spectra of 1-hexene. Similarly, there are some usefully characteristic differences in the corresponding normal NR mass spectra (Figure 5). With a 70-V deflector potential, the ARNR mass spectra show further differences reflecting the favored higher energy dissociations. The rearrangement peaks corresponding to $\mathrm{C}_{3} \mathrm{H}_{6}^{+}$- and $\mathrm{C}_{4} \mathrm{H}_{8}^{+}$- are substantially reduced, consistent with their entropic unfavorability. The recovery $\mathrm{C}_{6} \mathrm{H}_{12}^{+} \cdot$ molecular ion is the smallest for 1 hexene, whose heat of formation is $\sim 10 \mathrm{~kJ} \mathrm{~mol}{ }^{-1}$ [27] higher than the other two $\mathrm{C}_{6} \mathrm{H}_{12}$ isomers. Favorable allylic loss of ethyl from 2-hexene is consistent with the $\left[\mathrm{C}_{4} \mathrm{H}_{7}^{+}\right] /\left[\mathrm{C}_{5} \mathrm{H}_{9}^{+}\right]$values, which is highest for the ARNR spectrum of 2-hexene; however, this ratio is lowest for 1-hexene, not 3-hexene, for which allylic loss of methyl should be favored.

\section{Sensitivity}

Increasing the deflector potential from 0 to $70 \mathrm{~V}$ reduces the total NR ion intensity by approximately an order of magnitude. The efficiency should be far less 


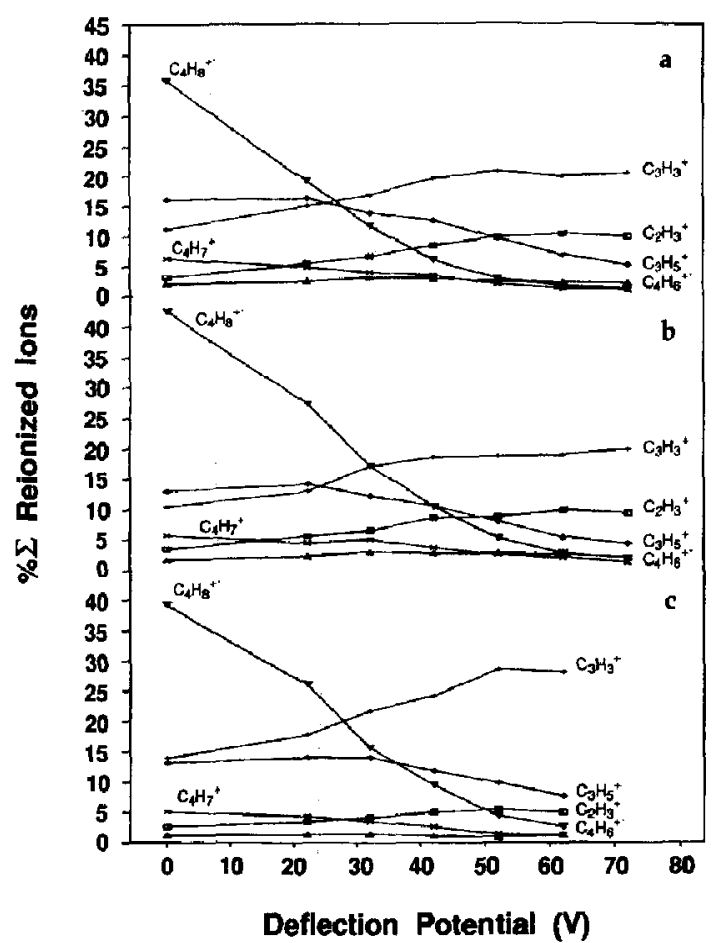

Figure 4. Relative abundances in the NR spectra, $\mathrm{Hg}(75 \% \mathrm{~T}) /$ $\mathrm{O}_{2}(50 \% \mathrm{~T})$ of (a) 1-butene, (b) E-2-butene, and (c) 2-methylpropene as a function of deflection potential.

for collection of products scattered only in the $z$-axis; however ${ }_{f}$ ion products from $y$-axis scattering with a sufficient $z$-axis component should still be focused by the Einzel lens to be collected. Thus most products from 70-V deflection arise from scattering angles $>$ $0.3^{\circ}$. Using neutralization by sodium or other low IP agents can increase the proportion of the desired high energy reactions in the unscattered NR spectrum by orders of magnitude, but of course a high proportion of these desired products could still be lost by scattering; we have not yet compared ARNR spectra from $\mathrm{Na}$ versus $\mathrm{Hg}$ neutralization. The $\mathrm{C}_{4} \mathrm{H}_{8}^{+}$. AKNR spectra reported here are clearly valuable for isomer characterization, but not as valuable as the Na-neutralization NR spectra reported earlier [8].

Greatly improved sensitivity and angular selectivity should be possible for ARNR spectra by angular selection of the $y$-axis-scattered neutrals before reionization, omitting deflection of the precursor ions [2]. However, this would require additions to the present MS-I ion optical system to maximize $y$-axis collimation of the ion beam entering the neutralization chamber to minimize the $y$-width of the neutral beam at the selection point. Neutralization-reionization mass spectrometry sensitivity and selectivity far greater than any now achievable could be possible with this improved experimental system by using the low IP neutralization agent most favorable for the desired neu-
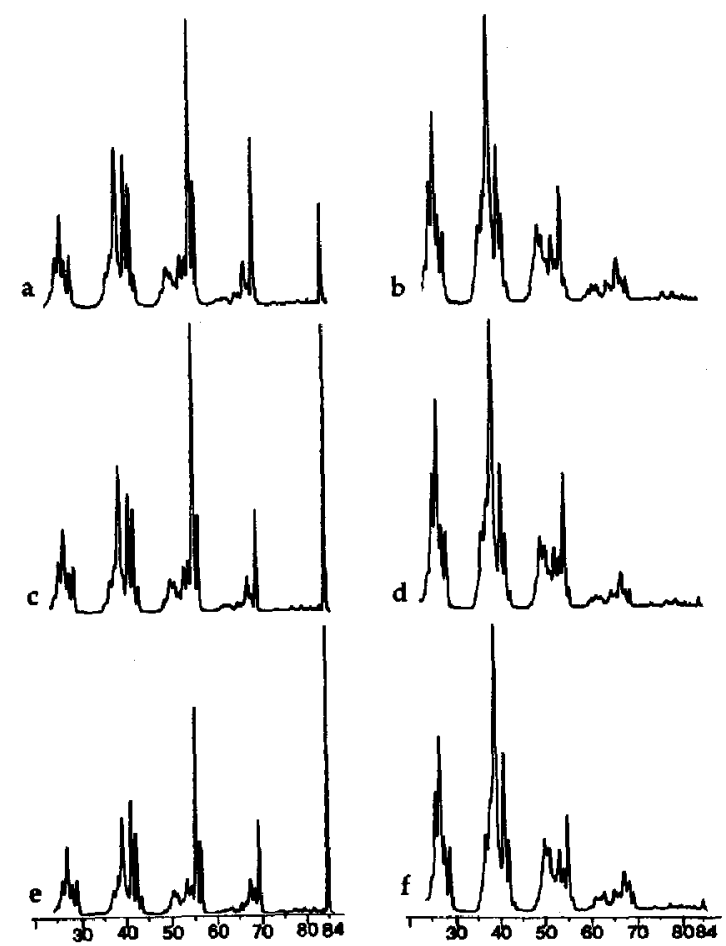

Figure 5. NR spectra $\mathrm{Hg}(75 \% \mathrm{~T}) / \mathrm{O}_{2}(50 \% \mathrm{~T})$ of (a and b) 1hexene, ( $c$ and $d$ ) E-2-hexene, and ( $e$ and $f$ ) E-3-hexene using deflection potentials of $(a, c$, and e) $0 \mathrm{~V}$ and $(b, d$, and $f) 70 \mathrm{~V}$.

tral dissociation. For example, using $\mathrm{Na}$ for $1-\mathrm{C}_{4} \mathrm{H}_{8}$ $\rightarrow \cdot \mathrm{C}_{3} \mathrm{H}_{5}+\cdot \mathrm{CH}_{3}[8]$ would not only produce a much larger proportion of the desired $\cdot \mathrm{C}_{3} \mathrm{H}_{5}$ product, but choosing a scattering angle corresponding to this reaction's energy release could also make possible the collection of a much higher proportion of the ${ }^{-} \mathrm{C}_{3} \mathrm{H}_{5}$ products formed. This $y$-axis selection of neutrals would also minimize the preferential collection of scattered ions.

\section{Conclusions}

As shown by Cooks and others [14-24], for ion dissociations evidenced in CAD mass spectra, selection of neutral dissociation products formed at increasing scattering angles provides an additional method to increase the relative abundance of products formed by higher energy neutral dissociations in NR mass spectra. The examples cited here show that this can be particularly useful in emphasizing simple dissociation reactions more characteristic of structure because rearrangements are minimized.

Experimentally, acquiring such ARNR mass spectra requires only the addition of a simple vertical electrostatic deflector, whereas the experimental problems in using alkali metal vapors for neutralization [8] apparently are the reason for the minimal use of this method 
to date [3-6]. Although the latter method $[2,8,25]$ has the important advantage of much greater sensitivity, direct angular selection of the neutrals scattered in the beam's narrow axis should give substantial improvements in ARNRMS selectivity as well as sensitivity.

\section{Acknowledgments}

D. E. Drinkwater and M.-Y. Zhang provided helpful suggestions; the National Science Foundation (grants CHE-8616907 and CHE-9014883) provided generous fnancial support; and the National Institutes of Health (grant GM-16609) provided partial instrumental funding.

\section{References}

1. Danis, P. O.; Wesdemiotis, C.; McLafferty, F. W. I. Am. Chem. Soc. 1983, 105, 7454-7456.

2. Gellene, G. I.; Porter, R. F. Acc. Chem. Res. 1983, 16, 200-207.

3. Wesdemiotis, C.; McLafferty, F. W. Chem. Rev. 1987, 87, 485-500.

4. Terlouw, J. K.; Schwarz, H. Angew. Chem. Int. Ed. Engl. 1987, 26, 808-815.

5. Holmes, J. L. Mass Spectrom. Rev. 1989, 8, 513-539.

6. McLafferty, F. W. Science (Washington, DC) 1990, 247, 925-929.

7. Zhang, M.-Y.; Wesdemiotis, C.; Marchetti, M.; Danis, P. O.; Ray, J. C., Jr.; Carpenter, B. K.; McLafferty, F. W. J. Am. Chem. Soc. 1989, 111, 8341-8346.

8. Feng, R.; Wesdemiotis, C.; Zhang, M.-Y.; Marchelli, M.; McLafferty, F. W. J. Am. Chem. Soc. 1989, 111, 1986-1991.

9. Wesdemiotis, C.; Leyh, B.; Fura, A.; McLafferty, F. W. I. Am. Chem. Soc. 1990, 112, 8655-8660

10. Zhang, M.-Y., McLafferty, F, W. J. Am, Soc. Mass Spectrom. Manuscript submitted for publication.

11. MeLafferty, F. W.; Kornfeld, R.; Haddon, W. F.; Levsen, K.; Sakai, I.; Bente, P. F., III; Tsai, S.-C.; Schuddemage, H D. R. I. Am. Chem. Soc. 1973, 95, 3886

12. McLafferty, F. W.; Wesdemiotis, C. Org. Mass Spectrom $1989,24,663-668$.
13. Turecek, F.; McLafferty, F. W.; Smith, B. J.; Radom, L. Int. J. Mass Spectrom. Ion Processes 1990, 101, 283-300.

14. Cooks, R. G.; Kim, K. C.; Bcynon, J. H. Chem. Phys. Lett. 1973, 23, 190

15. Laramee, J. A.; Carmody, J. J.; Cooks, R. G. Int. T. Mass Spectrom. Ion Phys. 1979, 31, 333-343.

16. Hubik, A. R.; Hemberger, P. H.; Laramee, J. A.; Cooks, R. G. J. Am. Chem. Soc. 1980, 102, 3997-4000.

17. Mason, R. S.; Francombe, M. J.; Jennings, K. R.; Cooks, R. G. Int. J. Mass. Spectrom. Ion Phys. 1982, 43, 327-330.

18. Verma, S.; Ciupek, J. D.; Cooks, R. G. Int. J. Mass Spectrom. Ion Processes 1984, 62, 219-225.

19. Horning, S. R.; Vincenti, M.; Cooks, R. G. J. Am. Chem. Soc. 1990, 112, 119-126.

20. Todd, P. J.; Warmack, R, J.; McBay, E. H. Int. J. Mass. Spectrom. Ion Phys. 1983, 50, 299-313.

21. Boyd, R. K.; Kingston, E. E.; Brenton, A. G.; Beynon, J. H. Proc. R. Sac. Lond. A 1984, 392, 59-88; 89-106.

22. Zwinselman, J. J.; Nacson, S.; Harrison, A. G. Int. I. Mass Spectrom. Ion Processes 1985, 67, 93-108.

23. Moore, C.; Mason, R. S.; Jennings, K. R.; Evans, S. Int. J. Mass Spectrom. Lon Processes 1988, 86, 109-120.

24. Reid, C. J. Int. J. Mass Spectrom. Ion Processes 1990, 101, 35-63.

25. Feng, R.; Wesdemiotis, C.; Baldwin, M. A.; McLafferty, F. W. Int. I. Mass Spectrom. Ion Processes 1988, 86, 95-107.

26. Dahl, D. A.; Delmore, J. E. Simion 4.0, EG and G Idaho Inc, EGC-CS-7233, Rev. April 2, 1988.

27. Lias, S. G.; Bartmess, J. E.; Liebman, J. F.; Holmes, J. L.; Levin, R. D.; Mallard, W. G. 1. Phys. Chem. Ref. Data, Suppl. No. 1, 1988, 17.

28. McLafferty, F. W.; Stauffer, D. B. Wiley/NBS Registry of Mass Spectral Data; Wiley: New York, 1989.

29. Nishishita, T.; Bockhoff, F. M.; McLafferty, F. W. Org. Mass Spectrom. 1977, 12, 16-20.

30. Guckert, J. R.; Carr, R. W. I. Phys. Chem. 1986, 90, 5679-5684.

31. Benson, S. W. Thermochemical Kinetics, 2nd ed.; Wiley: New York, 1976.

32. Rosenstock, H. M.; Draxl, K.; Steiner, B. W.; Herron, I. 'I'. J. Phys. Chem. Ref. Data, Suppl. No. 1, 1977, 6.

33. Nishishita, T.; McLafferty, F. W. Org. Mass Spectrom. 1977 12, 75-77 